Article

\title{
Investigation of Accidents during Storage Caused by Fermentation or Oxidation from SSSR and Fishmeal Using Thermal Analysis and Frank-Kamenetskii Theory
}

\author{
Naoharu Murasawa ${ }^{1,2, *}$, Hiroshi Koseki ${ }^{3}$, Yusaku Iwata ${ }^{3}$ and Takabumi Sakamoto ${ }^{4}$ \\ 1 Faculty of Risk and Crisis Management, Chiba Institute of Science, 3 Shiomi-Cho, Choshi, \\ Chiba 288-0025, Japan \\ 2 Fukushima Prefectural Center for Environmental Creation, 10-2 Fukasaku, Miharu-machi, \\ Fukushima 963-7700, Japan \\ 3 National Research Institute of Fire and Disaster, 4-35-3, Jindaiji-Higashimachi, Chofu, Tokyo 182-8508, Japan; \\ koseki@fri.go.jp (H.K.), iwata@fri.go.jp (Y.I.) \\ 4 College of Risk and Crisis Management, Kurashiki University of Science and the Arts, \\ 2640 Tsurajimamachi NishinoUra, Kurashiki, Okayama 712-8505, Japan; tsakamot@rcm.kusa.ac.jp \\ * Correspondence: n-murasawa@cis.ac.jp; Tel.: +81-0479-30-4500
}

Received: 17 April 2018; Accepted: 31 May 2018; Published: 2 June 2018

\begin{abstract}
In Japan, where soy sauce production and the fishery industries thrive, soy sauce squeezing residue (SSSR) and fishmeal, which are operational byproducts of these sectors, are produced as waste materials for recycling. SSSR and fishmeal have resulted in accidents due to spontaneous ignition and oxygen deprivation, which are believed to have been caused by the heat generated through fermentation or oxidation; consequently, it is desirable to develop measures that prevent such accidents during storage and transportation. In this study, we assessed the hazards associated with the spontaneous ignition and oxygen deprivation of SSSR and fishmeal in storage areas using thermal and gas analysers, focusing on the heat produced by fermentation and oxidation. We also used Frank-Kamenetskii theory to determine the relationship between pile height and the ambient temperatures at which spontaneous ignition and oxygen deprivation occur. Our results suggest that oxygen deficiency may occur in a well-sealed storage facility in which oxygen is consumed by fermentation. For example, the oxygen concentration can drop below critical safety thresholds in the case of SSSR, even when stored below $25^{\circ} \mathrm{C}$, particularly when the moisture content is high. However, when a sufficient amount of oxygen is present and the material is stored in large deposits in a well-insulated facility, fermentation causes the temperature to increase, leading to the oxidation of fatty acid esters and eventually fire; when SSSR or fishmeal is maintained at temperatures near $40{ }^{\circ} \mathrm{C}$, their temperatures can increase to $250{ }^{\circ} \mathrm{C}$ within approximately $30 \mathrm{~h}$. Furthermore, the results of this study also demonstrate the need to consider pile height in storage areas in order to prevent accidents due to spontaneous ignition and oxygen deprivation; the critical ambient temperature at which heat accumulates is estimated to be between $20-30{ }^{\circ} \mathrm{C}$, at a bulk density of $0.3 \times 10^{3} \mathrm{~kg} / \mathrm{m}^{3}$, and a pile height of $3 \mathrm{~m}$.
\end{abstract}

Keywords: accidents during storage; fermentation; oxidation; thermal and gas analysers; Frank-Kamenetskii theory

\section{Introduction}

The '3Rs' principle (reduce, reuse, and recycle) of waste management is the basis for a sustainable society in Japan, and techniques for implementing the 3Rs are constantly improving. Waste that is 
typically difficult to recycle can be effectively utilised as heat energy, in the form of electricity or steam, through incineration. However, even with advances in recycling research, recycled materials can still pose safety hazards during production, distribution, and storage if they are not fully assessed for potential dangers [1-4].

In Japan, recent years have been marked by widespread efforts to recycle and effectively use waste generated by the industry [5-7]. Soy sauce production and the fishery industries thrive in Japan, and soy sauce squeezing residue (SSSR) and fishmeal, which are the operational byproducts of these sectors, are produced as waste and recycling materials. For example, SSSR can be incinerated and reused in the form of thermal energy. Moreover, fishmeal is used as fertiliser as well as in pet food. However, SSSR and fishmeal can spontaneously ignite during storage and transportation. In addition, SSSR causes oxygen deficiency in storage areas due to fermentation, reportedly resulting in the deaths of workers [8]. Therefore, it is desirable to develop measures that prevent accidents resulting from spontaneous ignition and oxygen deprivation during the storage and transportation of SSSR and fishmeal. In this study, we conducted field surveys of storage locations that have been oxygen deficient and where fires have occurred.

To investigate the causes of these phenomena, we collected samples from these storage locations and applied various heat-analysis and gas-analysis methods with the objective of obtaining fundamental data that would inform future fire-prevention and oxygen-deficiency-prevention strategies. Based on the experimental results obtained, we used Frank-Kamenetskii theory [9] to determine the relationship between pile height and the ambient temperature at which spontaneous ignition and oxygen deprivation occur.

Moreover, the aim of this research was to develop an understanding of the circumstances leading to spontaneous-ignition and oxygen-deficiency accidents in storage facilities, and to recommend the safety measures that prevent such occurrences.

\section{Experimental}

For a variety of reasons, thermal analysis was used to investigate the causes of the accidents described above. With just a small sample of a material ( $1 \mathrm{~g}$ or less), its properties can be studied in order to prevent the occurrence of fire, large quantities of poisonous gas, and smoke. The data obtained through thermal analysis also aids in targeted risk assessment, placing the principal focus on materials that are likely to generate heat when piled.

The relative sensitivities of the thermal-analysis equipment used in this study, the details of which are provided below, are summarised in Table 1. The relative sensitivities of equipment are given in $\mu \mathrm{W}$ in the table; lower relative sensitivities correspond to a higher detection performance. The relative sensitivity was calculated by energy calibration. The bomb-type calorimeter and gas chromatograph used in this study are excluded, since their sensitivities cannot be expressed in a manner that is consistent with the other equipment.

Table 1. Working modes and test conditions of the calorimeters employed in this study.

\begin{tabular}{ccccc}
\hline Calorimeter * & Absolute Sensitivity $(\mu \mathbf{W})$ & $\begin{array}{c}\text { Volume of } \\
\text { Vessel }(\mathbf{m L})\end{array}$ & $\begin{array}{c}\text { Measureable Temperature } \\
\text { Range }\left({ }^{\circ} \mathbf{C}\right)\end{array}$ & Working Mode \\
\hline TG-DTA & $10-30$ & 0.05 & $\sim 1000$ & Heating \\
C80 & 2 & 8 & $\sim 300$ & Heating \\
TAM & 0.2 & 4 & $\sim 150$ & Isothermal \\
SIT & $5-10$ & 2 & $\sim 300$ & Adiabatic \\
Wire-mesh cube & Thermocouple dependent & 1000 & $\sim 1000$ & Isothermal \\
\hline
\end{tabular}

* Details of the equipment used are provided in Sections 2.2-2.6. 


\subsection{Samples}

Large amounts of SSSR are produced when moromi (unrefined soy sauce) is compressed to extract the raw soy sauce. SSSR is plate-shaped when produced, but is later finely ground for storage and processing (Figure 1). Fishmeal refers to the crushed powder obtained by boiling residual fish substances during the removal of water and oil from the residue, with subsequent pressing, and eventually drying of the remaining solid with hot air or steam (Figure 2).

For some experiments, distilled water was added to the sample (equal to $20 \%$ of the sample mass) in order to examine the effects of additional moisture on fermentation and the thermal properties of the sample. In addition, samples were subjected to a 17-h sterilisation treatment using ethylene oxide gas (EOG) to ascertain the effects of fermentation. EOG is widely used to sterilise medical devices and precision machinery, and kill microorganisms [10]. Moreover, to ascertain the influence of fat and oil, samples was defatted by Soxhlet extraction over a period of $6 \mathrm{~h}$ using diethyl ether as solvent.

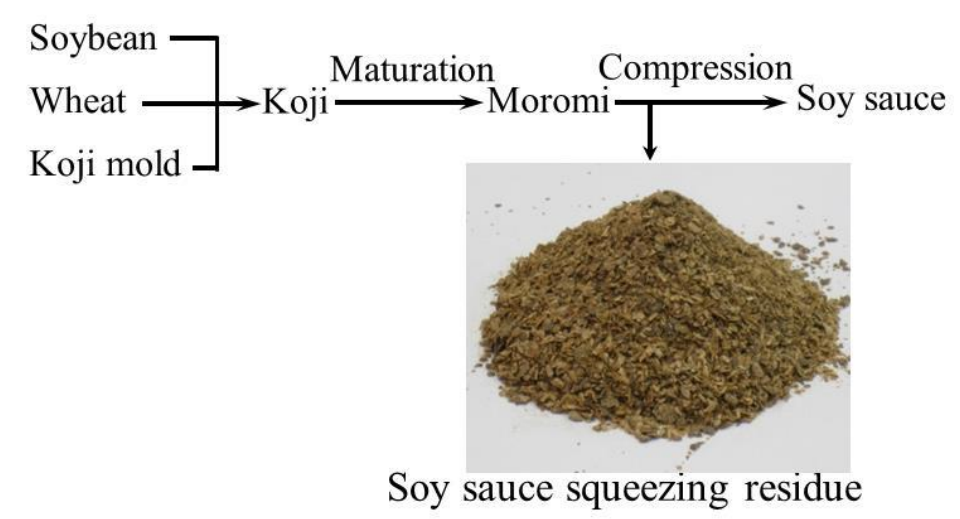

Figure 1. Production of soy sauce squeezing residue (SSSR).

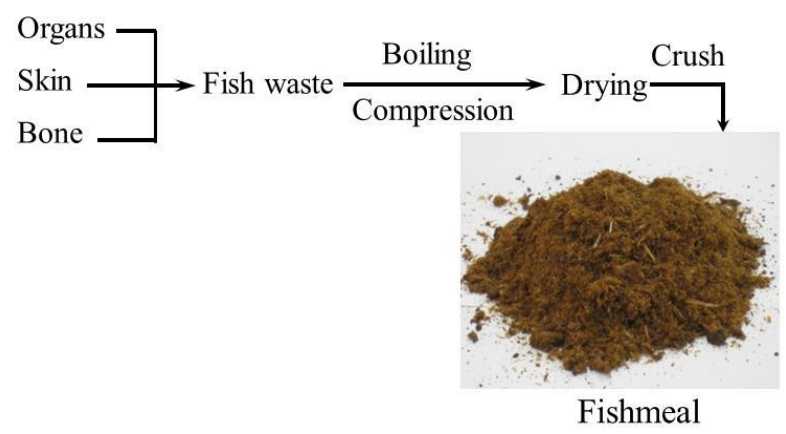

Figure 2. Production of fishmeal.

\subsection{Thermogravimetric Differential Thermal Analysis}

Thermogravimetric differential thermal analysis (TG-DTA) (Rigaku Thermoplus TG 8120, Rigaku, Tokyo, Japan) was used to study the overall thermal properties of the samples. Each sample $(\sim 20 \mathrm{mg})$ was placed in an open aluminium container $(0.05 \mathrm{~mL})$, after which it was heated from room temperature to $600{ }^{\circ} \mathrm{C}$ at a rate of $2{ }^{\circ} \mathrm{C} / \mathrm{min}$, under a $150 \mathrm{~mL} / \mathrm{min}$ stream of air.

\subsection{Calvet Calorimetry}

A Calvet calorimeter (Setaram C80, France) was used for additional thermal experiments. The C80 calorimeter is a highly sensitive twin-type heat-flux calorimeter. It can reduce the effects of the vaporisation of water contained in the sample by using a high-pressure closed vessel $(8 \mathrm{~mL})$, and can take measurements from room temperature up to $100^{\circ} \mathrm{C}$, which is a temperature range that cannot 
easily be examined by TG-DTA. Samples $(\sim 1.5 \mathrm{~g})$ in sealed vessels were heated from room temperature to $300^{\circ} \mathrm{C}$ at a rate of $0.1^{\circ} \mathrm{C} / \mathrm{min}$.

\subsection{High-Sensitivity Isothermal Calorimetry}

We used a highly sensitive isothermal calorimeter (Thermometric TAM-III, Sweden) to examine in detail the low levels of heat generated through the fermentation and oxidation of fatty acid esters. The TAM calorimeter measures the amount of heat generated by microbial fermentation on the nanoscale. Samples $(1.0 \mathrm{~g})$ were placed in sealed containers $(4 \mathrm{~mL})$, which were isothermally maintained at $50{ }^{\circ} \mathrm{C}$ for $3 \mathrm{~d}$.

\subsection{Spontaneous Ignition Testing (under Adiabatic Conditions)}

To consider the transition from self-heating to spontaneous ignition, a more advanced detector is required. We used a spontaneous ignition tester (SIT) (Shimadzu SIT-2, Kyoto, Japan) to test for materials that are susceptible to spontaneous ignition under adiabatic conditions [11], in which heat loss to the surroundings is minimised, and the heat liberated from exothermic reactions is used in the self-heating process. Figure 3 shows a schematic diagram of the device. After setting the oven temperature of the tester, each sample $(\sim 1.5 \mathrm{~g})$ was placed in the oven under a $5 \mathrm{~mL} / \mathrm{min}$ flow of nitrogen to prevent the sample from reacting. Air, at a rate of $2 \mathrm{~mL} / \mathrm{min}$, was then introduced, and the temperature was recorded. If no temperature increase was observed after $120 \mathrm{~h}$ at the set temperature, the test was considered to be complete.

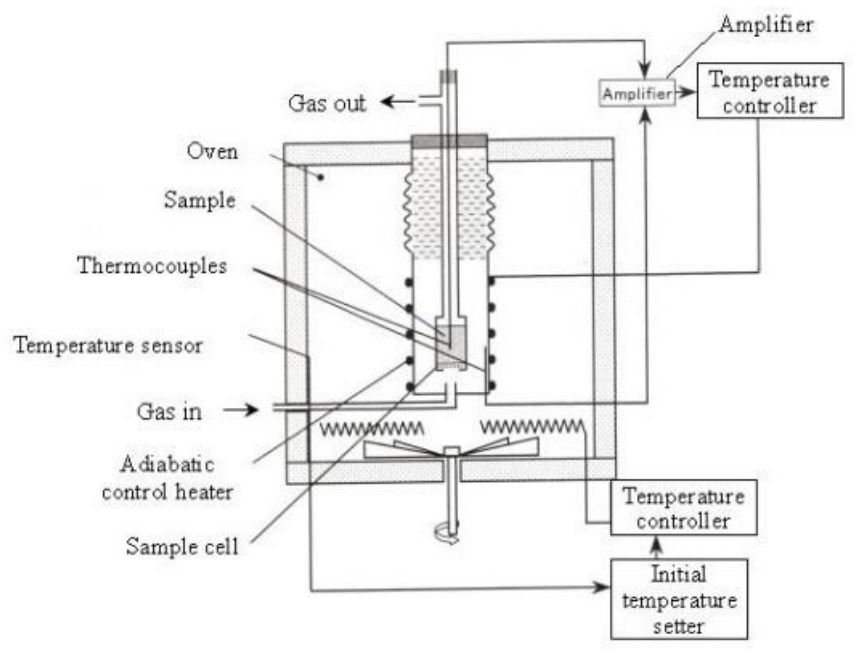

Figure 3. Schematic diagram of the spontaneous-ignition tester used in this study.

\subsection{Wire-Mesh Cube Testing (Isothermal Conditions)}

In order to understand the circumstances surrounding spontaneous ignition, wire-mesh cube testing (Figure 4) was performed in accordance with the United Nations Recommendations on the Transport of Dangerous Goods. This test was designed to determine the risk of fire when a solid material retains heat in air at a given temperature [12]. To study combustion behaviour and hazards following the onset of thermal decomposition, a 400-g sample, which is equivalent to approximately 800 times the weight used during spontaneous-ignition testing, was placed in a cubic sample vessel (wire basket) with side lengths of $10 \mathrm{~cm}$, after which it was placed in a constant-temperature bath. The temperature of the central section of the vessel was measured to determine whether or not the temperature increased by over $60^{\circ} \mathrm{C}$ within $24 \mathrm{~h}$, compared to the pre-set temperature. Testing was terminated if no temperature increase, from the pre-set ambient temperature, was observed over a 24-h period. 


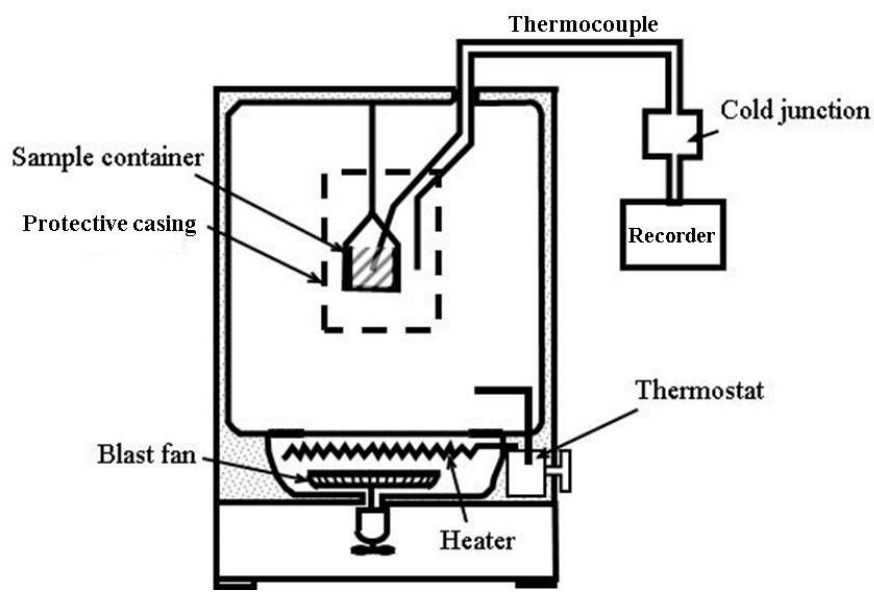

Figure 4. Schematic diagram of the wire-mesh cube tester.

\subsection{Bomb-Type Calorimeter}

In order to understand the combustion severity and risk of fire in a sample, the heat of combustion was measured using a bomb-type calorimeter (IKA C2000, Germany). The sample ( 500 mg) was completely burned inside the bomb cylinder, which was filled with hyperbaric oxygen. The heat generated was completely absorbed by the water in the tank surrounding the cylinder, from which the heat of combustion was measured. A schematic diagram of the C2000 calorimeter is shown in Figure 5.

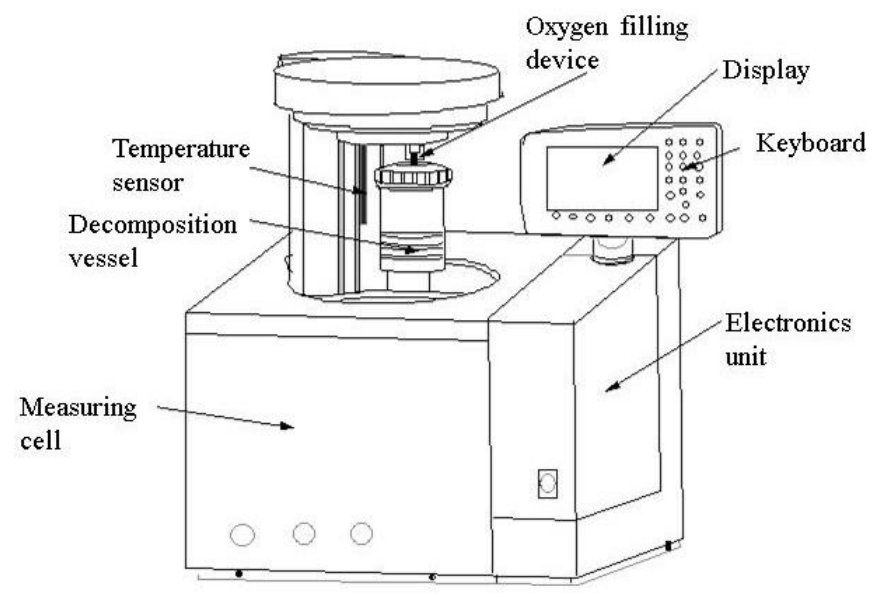

Figure 5. Schematic diagram of the bomb-type calorimeter.

\subsection{Gas Chromatography}

To study gas emissions during storage, the sample material $(\sim 50 \mathrm{~g})$ was placed in an airtight 1-L glass bottle and placed in a thermostatically controlled oven. The gas produced was collected and examined using a gas chromatograph (Shimadzu, GC-14B, Japan) fitted with a thermal conductivity detector (TCD, $200{ }^{\circ} \mathrm{C}, 50 \mathrm{~mA}$ sensitivity, $20 \mathrm{~mL} / \mathrm{min}$ Ar carrier gas); a standard gas (CO: $0.0500 \%, \mathrm{C}_{2} \mathrm{H}_{6}$ : $0.995 \%, \mathrm{H}_{2}: 0.097 \%, \mathrm{CO}_{2}: 0.996 \%, \mathrm{CH}_{4}: 0.987 \%$ ) was used for calibration purposes. SHINCARBON-ST (Shinwa Chemical Industries, $2.0 \mathrm{~m} \times 3.0 \mathrm{~mm} \phi$, Kyoto, Japan) was used for the column. The column temperature was increased from $40{ }^{\circ} \mathrm{C}(6 \mathrm{~min}$ hold $)$ to $80^{\circ} \mathrm{C}(12 \mathrm{~min}$ hold $)$ and then to $150{ }^{\circ} \mathrm{C}(10 \mathrm{~min}$ hold) at a rate of $40{ }^{\circ} \mathrm{C} / \mathrm{min}$. An air cylinder $\left(\mathrm{O}_{2}: 21 \%, \mathrm{~N}_{2}: 79 \%\right)$ was used as the standard gas for the determination of $\mathrm{O} 2$ and N2; a TCD $\left(200{ }^{\circ} \mathrm{C}, 30 \mathrm{~mA}\right.$ sensitivity, $20 \mathrm{~mL} / \mathrm{min}$ Ar carrier gas) and a $30{ }^{\circ} \mathrm{C}$ isothermal column temperature were used. 


\section{Results and Discussion}

\subsection{Thermogravimetric Differential Thermal Analysis}

Figures 6 and 7 display TG-DTA traces for SSSR and fishmeal, respectively, recorded at a scan rate of $2{ }^{\circ} \mathrm{C} / \mathrm{min}$. The decomposition temperatures correspond to the points at which the DTA traces shift by $0.1 \mu \mathrm{V}\left(0.01^{\circ} \mathrm{C}\right)$ in the heat-generation direction from the constant baseline.

The downward direction in the DTA trace indicates an endothermic reaction, while the upward direction corresponds to an exothermic reaction. The thermal decompositions of SSSR and fishmeal are divided into three phases. Due to dehydration, a total weight decrease of $26 \%$ was observed from room temperature to $100{ }^{\circ} \mathrm{C}$ for SSSR, after which organic components decomposed and combusted over the $180{ }^{\circ} \mathrm{C}$ to $380^{\circ} \mathrm{C}$ range $[13,14]$. By the end of this phase, a total weight loss of about $70 \%$ was observed. The final stage is consistent with the decomposition and combustion of carbide, to leave a residue that weighed only $10 \%$ of the original sample weight.

Meanwhile, fishmeal displayed a $7.8 \%$ dehydration loss from room temperature to $100{ }^{\circ} \mathrm{C}$. Overall, fishmeal lost mass at a lower rate than SSSR, resulting in a smaller heat generation peak, but in a higher amount of final residue. Shifts that generated heat were observed at $172.9^{\circ} \mathrm{C}$ and $187.3^{\circ} \mathrm{C}$ for SSSR and fishmeal, respectively. These are, theoretically, the points at which combustion begins [15].

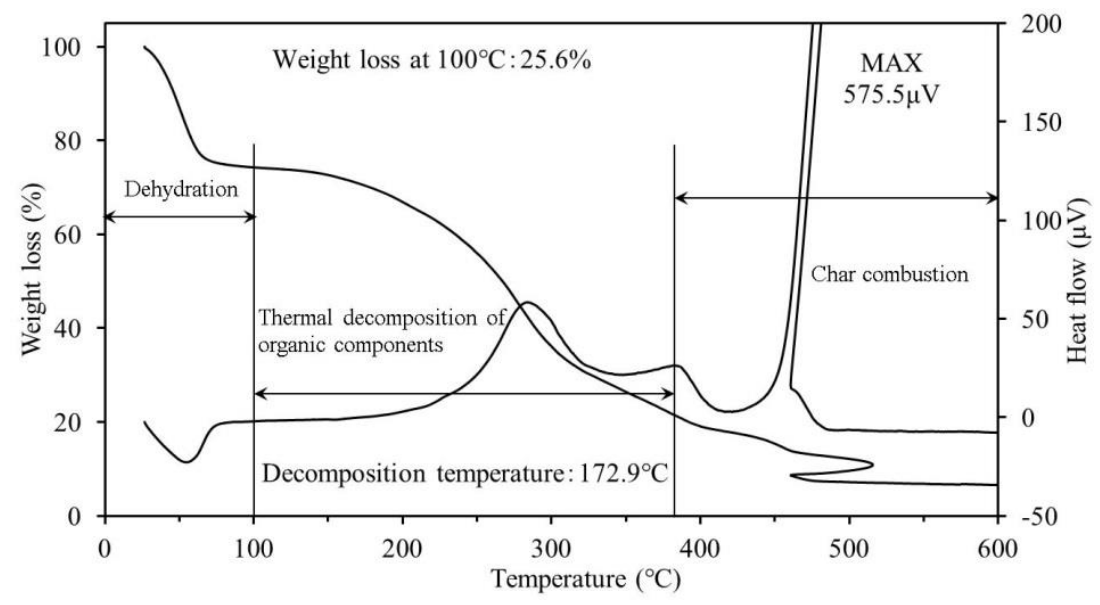

Figure 6. TG-DTA results for the SSSR sample.

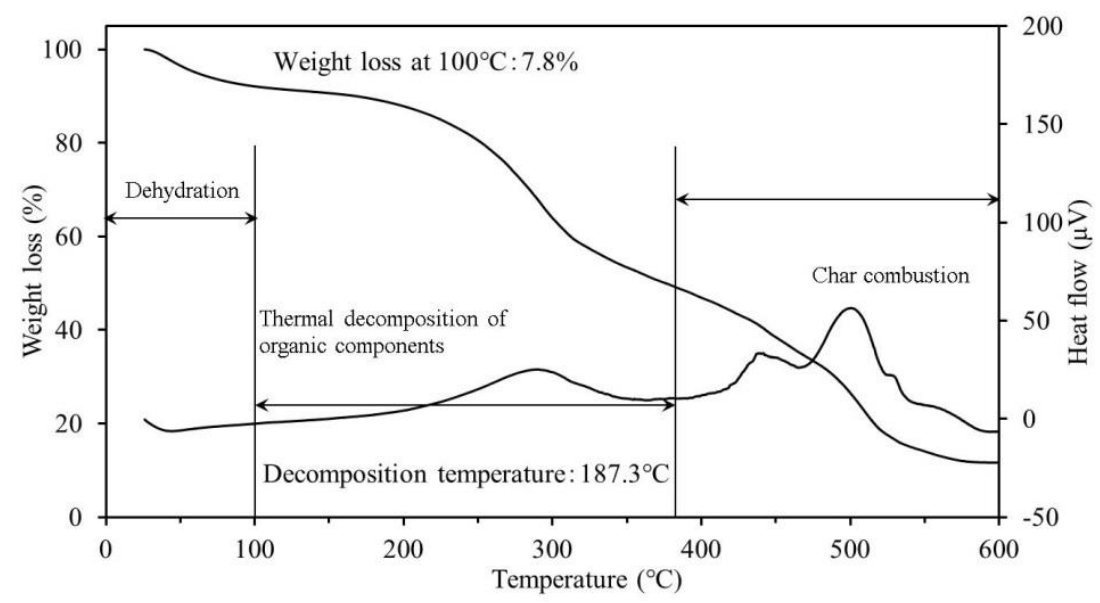

Figure 7. TG-DTA results for the fishmeal sample. 


\subsection{Calvet Calorimetry}

The C80 calorimeter is more sensitive than the TG-DTA system; consequently, a lower scan rate was used. As a result, detailed thermal-behaviour information, including the existence of low levels of heat generated at temperatures $\leq 100{ }^{\circ} \mathrm{C}$, which are difficult data to obtain by TG-DTA, can be obtained with the $\mathrm{C} 80$ calorimeter.

Figures 8 and 9 show $\mathrm{C} 80$ calorimetry results at a scan rate of $0.1{ }^{\circ} \mathrm{C} / \mathrm{min}$; the heat-generation onset temperatures are summarised in Tables 2 and 3 for SSSR and fishmeal, respectively. The exothermic onset temperature was taken as the temperature at which the rate of generated heat increased to $0.005 \mathrm{~mW}$.

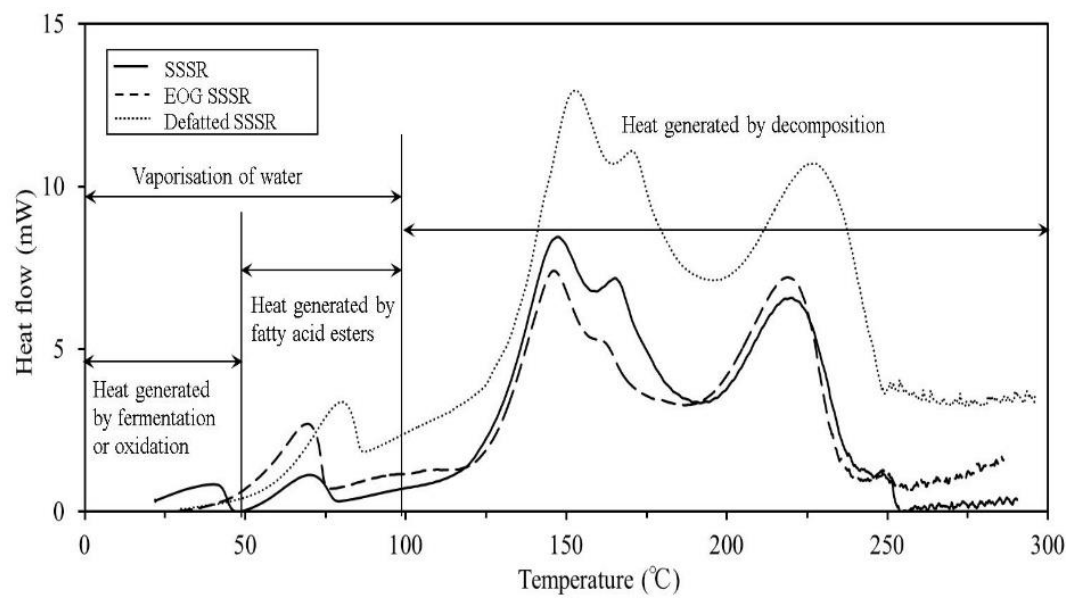

Figure 8. C80-calorimetry results for SSSR.

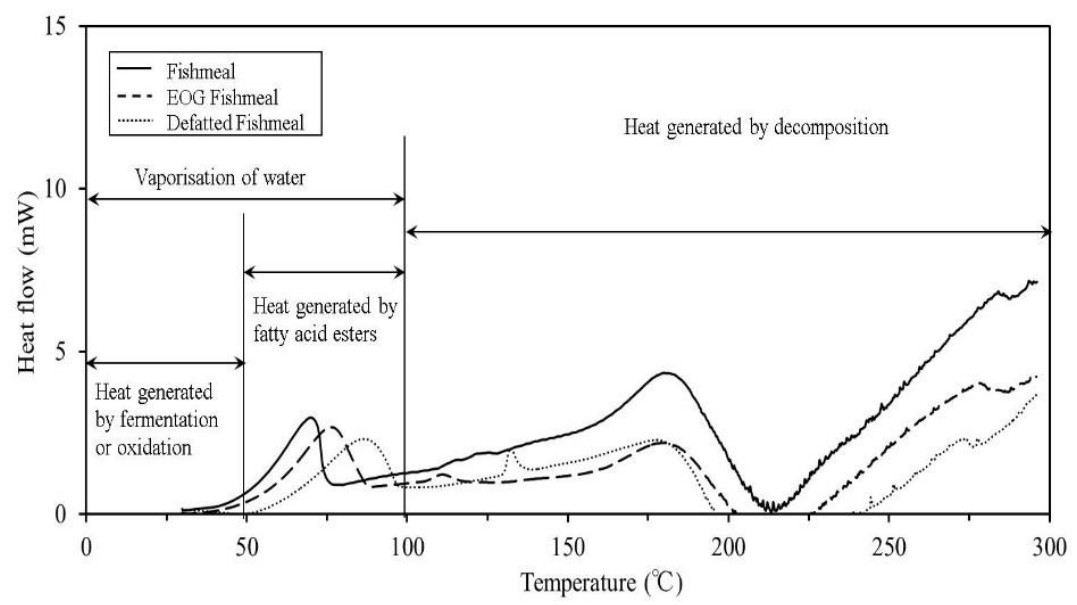

Figure 9. C80-calorimetry results for fishmeal.

The heat-generation onsets of unprocessed SSSR and fishmeal were below $30^{\circ} \mathrm{C}$. These results show that a fire can be caused through spontaneous ignition when conditions are conducive to heat accumulation, even when the materials are stored at temperatures near room temperature. Furthermore, the likelihood of reaching self-heat-generation temperatures is high when the rate of heat generated by fermentation and oxidation exceeds the rate of heat released externally.

No heat was generated between room temperature and $50{ }^{\circ} \mathrm{C}$ for the EOG-treated and sterilised SSSR, and for the SSSR defatted by diethyl ether. We attribute the result obtained for the defatted sample to the diminishment of fermentation microorganisms during the defatting process. 
With regards to the EOG-treated and sterilised fishmeal, the heat-generation onset temperature was only slightly higher than that of the untreated fishmeal, and the defatted fishmeal exhibited a heat-generation onset temperature that was higher than those of untreated and EOG-treated fishmeal. By comparing the results from the SSSR and fishmeal at the start of the heat-generation period, we conclude that the heat generated by SSSR is largely the result of microbial fermentation, while the heat generated by fishmeal, although influenced by fermentation, is affected more by the oxidation of fat.

We attribute the heat generated in the $50-100{ }^{\circ} \mathrm{C}$ range to the oxidation of residual fat that could not be defatted under the present conditions, and to the oxidation of other components [16]. The heat generated through the oxidation of fatty acid esters was observed over the $80-100{ }^{\circ} \mathrm{C}$ temperature range for all of the samples. Above $100{ }^{\circ} \mathrm{C}$, the observed generation of heat is assumed to be caused by decomposition $[13,14]$.

Table 2. Heat-generation onset temperatures and total heat generated for SSSR (soy sauce squeezing residue) (room temperature to $100^{\circ} \mathrm{C}$ ).

\begin{tabular}{cc}
\hline Sample & Heat-Generation Onset Temperature $\left({ }^{\circ} \mathbf{C}\right)$ \\
\hline SSSR & 27.8 \\
EOG-treated SSSR & 53.8 \\
Defatted SSSR & 55.1 \\
\hline
\end{tabular}

Table 3. Heat-generation onset temperatures and total heat generated for fishmeal (room temperature to $100{ }^{\circ} \mathrm{C}$ ).

\begin{tabular}{cc}
\hline Sample & Heat-Generation Onset Temperature $\left({ }^{\circ} \mathrm{C}\right)$ \\
\hline Fishmeal & 41.2 \\
EOG-treated fishmeal & 42.3 \\
Defatted fishmeal & 51.3 \\
\hline
\end{tabular}

\subsection{High-Sensitivity Isothermal Calorimetry}

The results from the TAM-calorimetry experiments are shown in Figures 10 and 11 for SSSR and fishmeal, respectively, while Table 4 (SSSR) and Table 5 (fishmeal) summarise the amounts of heat generation over $0-24 \mathrm{~h}$ and $24-72 \mathrm{~h}$ time periods, and the combination of the two (i.e., $0-72 \mathrm{~h}$ ). The TAM-calorimeter holding temperature was set to $50{ }^{\circ} \mathrm{C}$, because microbial activity occurs at approximately this temperature and gradually decreases with increasing temperature [17]. In addition to experiments performed in a limited-air atmosphere, the same experiments were performed in a sealed sample vessel under nitrogen.

The amount of heat generated by microbial fermentation, which is the primary cause of the heat generated, can be increased further through the addition of water to the sample and allowing it to settle for a prolonged period, which increases microbial activity. Accordingly, the experiment was performed by adding approximately $20 \%$ water to a $10 \mathrm{~g}$ sample and maintaining $1 \mathrm{~g}$ of this sample at $25 \pm 5^{\circ} \mathrm{C}$ for $10 \mathrm{~d}$.

We observed a decrease in the heat generated by the SSSR sample following EOG treatment, but no such change was observed for the fishmeal. No significant heat was generated when the SSSR or the fishmeal were placed in sealed sample vessels under nitrogen.

Hence, we found that oxygen contributes to heat generation in SSSR and fishmeal at temperatures of around $50^{\circ} \mathrm{C}$. We observed that heat was generated in both SSSR and fishmeal in air immediately after the commencement of the experiment, after which it gradually declined. Although the maximum value of the heat generated by SSSR was higher, the difference between the amount of heat generated by SSSR and fishmeal was not significant. When the experiments commenced following the addition of water to the sample and $10 \mathrm{~d}$ of settling, a sharp exothermic peak $(2000 \mu \mathrm{W})$ was observed for SSSR, but not for fishmeal, immediately. 
However, this phenomenon was immediately followed by a converging trend ascribed to microbial proliferation resulting from the addition of water to the sample. Hence, the oxygen in the sealed sample vessel was consumed during the early stages of the experiment. Examination of the results of the experiments conducted under nitrogen, and those following EOG treatment, led to the following conclusions: fermentation has a greater effect in SSSR, whereas oxidation has a greater effect in fishmeal, with respect to the heat generated near $50{ }^{\circ} \mathrm{C}$. This observation is consistent with the C80-calorimetry results.

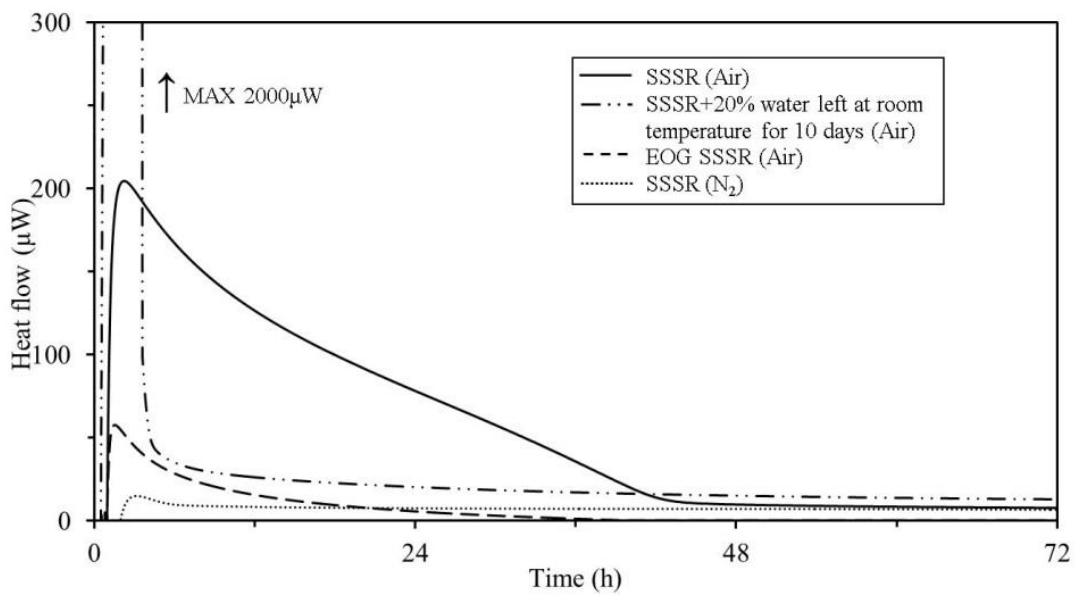

Figure 10. TAM-calorimetry results for SSSR.

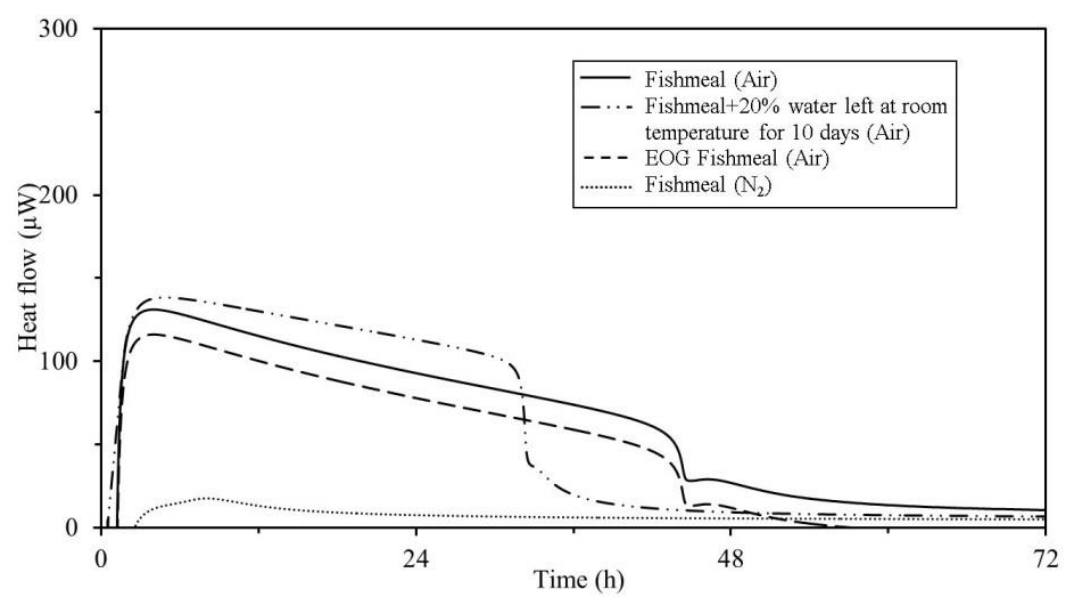

Figure 11. TAM-calorimetry results for fishmeal.

Table 4. Heat generated in SSSR at $50{ }^{\circ} \mathrm{C}$. EOG: ethylene oxide gas.

\begin{tabular}{|c|c|c|c|}
\hline Sample & $\begin{array}{l}\text { Heat Generated }(\mathrm{J} / \mathrm{g}) \\
0-24 \mathrm{~h}\end{array}$ & $\begin{array}{l}\text { Heat Generated }(\mathrm{J} / \mathrm{g}) \\
24-72 \mathrm{~h}\end{array}$ & $\begin{array}{l}\text { Heat Generated }(\mathrm{J} / \mathrm{g}) \\
0-72 \mathrm{~h}\end{array}$ \\
\hline SSSR (Air) & 11.1 & 4.2 & 15.3 \\
\hline $\begin{array}{l}\text { SSSR }+20 \% \text { water left at room } \\
\text { temperature for } 10 \mathrm{~d} \text { (Air) }\end{array}$ & 14.4 & 2.5 & 16.9 \\
\hline EOG SSSR (Air) & 2.6 & 1.3 & 3.9 \\
\hline $\operatorname{SSSR}\left(\mathrm{N}_{2}\right)$ & 0.7 & 1.2 & 1.9 \\
\hline
\end{tabular}


Table 5. Heat generated in fishmeal at $50{ }^{\circ} \mathrm{C}$.

\begin{tabular}{|c|c|c|c|}
\hline Sample & $\begin{array}{l}\text { Heat Generated }(\mathrm{J} / \mathrm{g}) \\
0-24 \mathrm{~h}\end{array}$ & $\begin{array}{l}\text { Heat Generated }(\mathrm{J} / \mathrm{g}) \\
\qquad 24-72 \mathrm{~h}\end{array}$ & $\begin{array}{l}\text { HeatGenerated }(\mathrm{J} / \mathrm{g}) \\
0-72 \mathrm{~h}\end{array}$ \\
\hline Fishmeal (Air) & 8.2 & 7 & 15.2 \\
\hline $\begin{array}{l}\text { Fishmeal }+20 \% \text { water left at } \\
\text { room temperature for } 10 \mathrm{~d} \text { (Air) }\end{array}$ & 11.6 & 5.3 & 16.9 \\
\hline EOG fishmeal (Air) & 10.6 & 4.9 & 15.5 \\
\hline Fishmeal $\left(\mathrm{N}_{2}\right)$ & 0.9 & 1 & 1.9 \\
\hline
\end{tabular}

\subsection{Spontaneous-Ignition Testing (Under Adiabatic Conditions)}

The C80 and TAM-calorimetry results strongly suggest that SSSR and fishmeal generate heat through fermentation and oxidation at approximately $50{ }^{\circ} \mathrm{C}$. To examine whether or not the accumulation of generated heat results in an increase in temperature that eventually causes fire, we used a SIT that is capable of reproducing the adiabatic conditions of high-volume storage [11]. Figures 12 and 13 display SIT curves for SSSR and fishmeal, respectively, at various environmental temperatures between room temperature and $100^{\circ} \mathrm{C}$, while Figures 14 and 15 show the analogous curves for initial temperatures between $100-200{ }^{\circ} \mathrm{C}$. A flat SIT curve is observed when no heat is generated from the sample, but a rise in sample temperature is observed as the sample begins to generate heat.

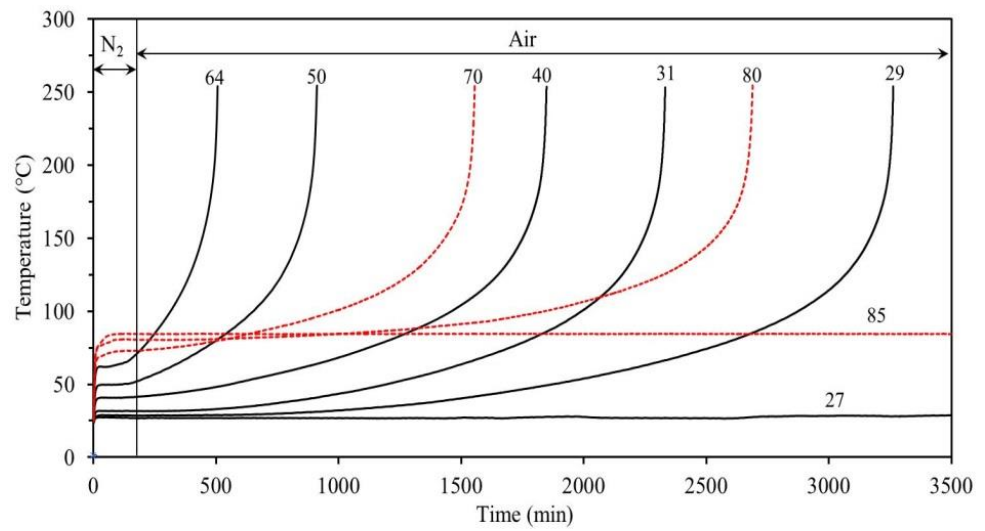

Figure 12. SIT curves for SSSR in the room-temperature to $100{ }^{\circ} \mathrm{C}$ range.

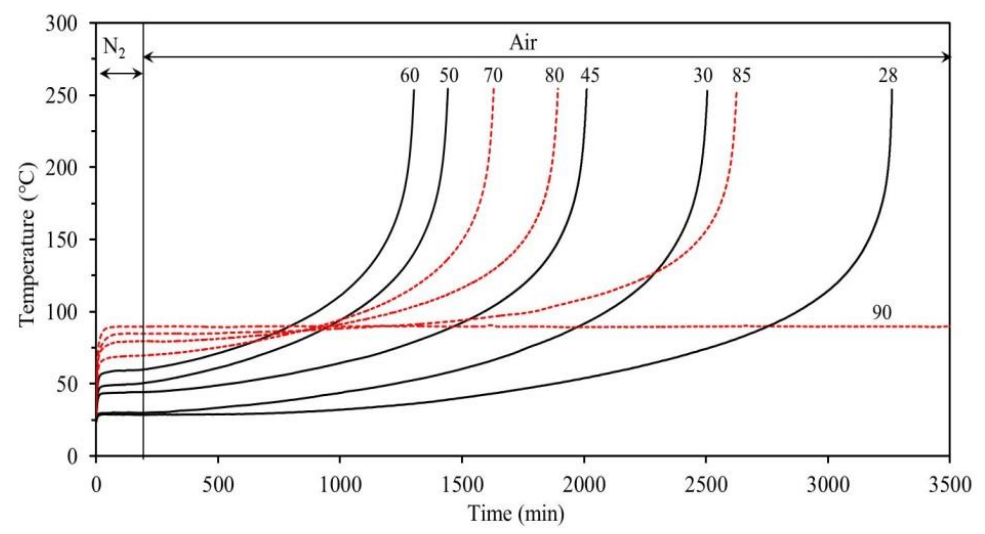

Figure 13. SIT curves for fishmeal in the room-temperature to $100{ }^{\circ} \mathrm{C}$ range.

These results reveal that the spontaneous ignition of SSSR or fishmeal depends on the ambient temperature. Under the conditions used in the present study, heat is not generated in the SSSR at ambient temperatures of $27^{\circ} \mathrm{C}$ and below. The minimum temperature at which spontaneous ignition 
was triggered lies between $27-29^{\circ} \mathrm{C}$. Between $29-64{ }^{\circ} \mathrm{C}$, the induction time prior to a decrease in the SSSR temperature decreases as the ambient temperature increases. Conversely, between $65-80{ }^{\circ} \mathrm{C}$, the induction time increases as the ambient temperature increases. Furthermore, between $85-130^{\circ} \mathrm{C}$, the SSSR temperature never rises above the maintained temperature. We believe that the temperature cannot rise within the timeframe of this study due to heat absorption through the evaporation or boiling of water. Moreover, as the ambient temperature is further increased, thermal cracking occurs, and an increase in the SSSR temperature is observed between $135-200^{\circ} \mathrm{C}$.

A comparison of the SSSR and fishmeal results reveals that SSSR requires a shorter time for its temperature to rise following heat generation, even when similar ambient temperatures are maintained. In addition, when either SSSR or fishmeal is maintained at an ambient temperature near $40{ }^{\circ} \mathrm{C}$, its temperature increases to $250^{\circ} \mathrm{C}$ within approximately $30 \mathrm{~h}$. Consequently, control of the temperature of industrial waste, such as SSSR and fishmeal, is necessary when large quantities are stored in closed warehouses during summer.

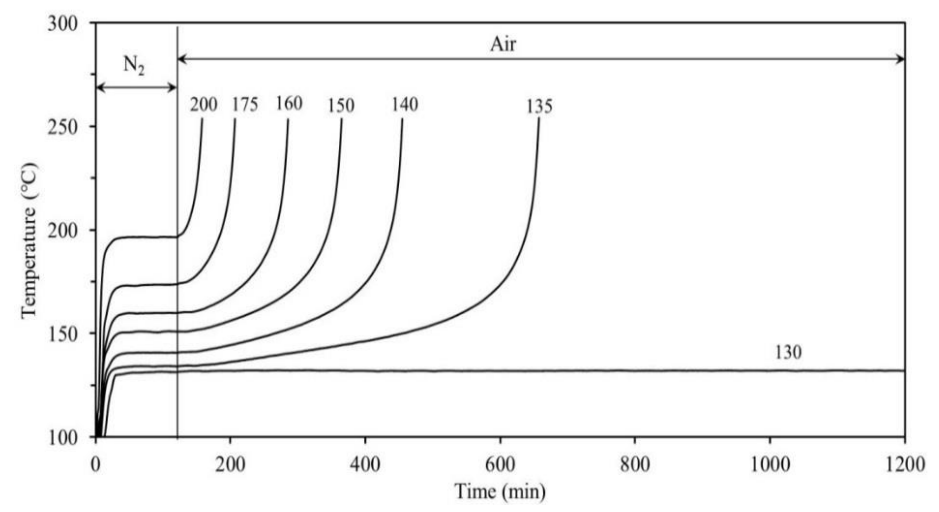

Figure 14. SIT curves for SSSR over the $100{ }^{\circ} \mathrm{C}$ to $200{ }^{\circ} \mathrm{C}$ range.

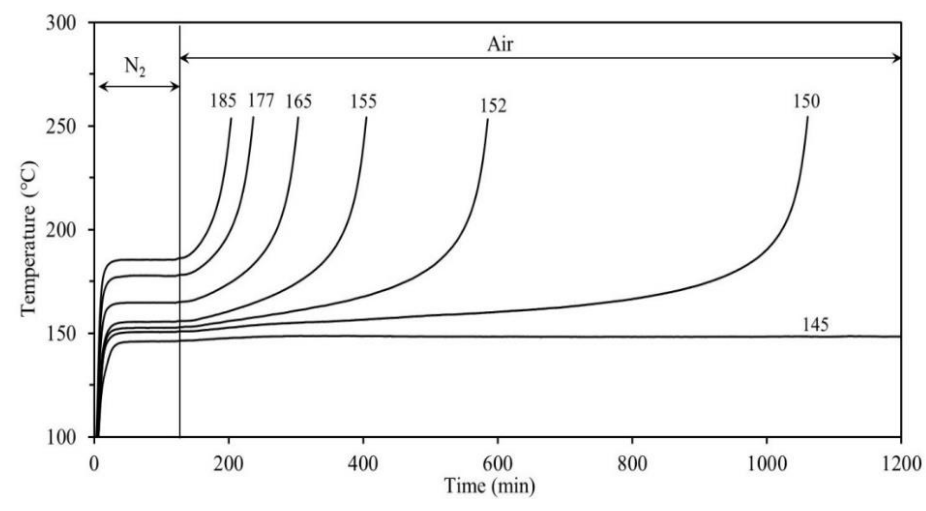

Figure 15. SIT curves for fishmeal over the $100{ }^{\circ} \mathrm{C}$ to $200{ }^{\circ} \mathrm{C}$ range.

\subsection{Wire-Mesh-Cube Testing}

Taking into account the results obtained from the TG-DTA and SIT experiments, we conducted wire-basket testing as prescribed by the United Nations Recommendations for the Transport of Dangerous Goods, in order to study the processes occurring between the onset of thermal decomposition and combustion in greater detail [12].

Samples weighing $400 \mathrm{~g}$, which is equivalent to approximately 800 times the weight used during SIT testing, were used in these experiments, the results of which are displayed in Figures 16 and 17 for SSSR and fishmeal, respectively; these traces represent the transitions from thermal decomposition following evaporation to combustion. Since the results reflect the oxidation of organic matter at high temperatures, the heat generated from fermentation at low temperatures is neglected. 
Thermal decomposition began at temperatures above $140{ }^{\circ} \mathrm{C}$ in both SSSR and fishmeal, which ultimately resulted in combustion. These values were almost identical to those obtained during SIT testing, as shown in Figures 14 and 15 (SSSR: $135^{\circ} \mathrm{C}$; fishmeal: $150^{\circ} \mathrm{C}$ ).

Possible reasons for the differences between these values and the thermal-decomposition onset temperatures obtained from TG-DTA (SSSR: $172.9^{\circ} \mathrm{C}$; fishmeal: $187.3^{\circ} \mathrm{C}$ ) include equipment sensitivity, measurement conditions (adiabatic versus non-adiabatic), and differences in sample volume. Moreover, these results, along with the $\mathrm{C} 80$-calorimetry results (above $100{ }^{\circ} \mathrm{C}$ ), indicate that thermal decomposition at these temperatures is likely to be responsible for the initial generation of heat.

There is a risk of combustion when the temperature approaches $140^{\circ} \mathrm{C}$. We observed that the heat generated in fishmeal had an earlier onset compared with that in SSSR at $140{ }^{\circ} \mathrm{C}$. However, the temperature increased rapidly once heat began to be generated in SSSR, ultimately resulting in combustion. Therefore, SSSR carries a greater risk of thermal decomposition leading to combustion than fishmeal.

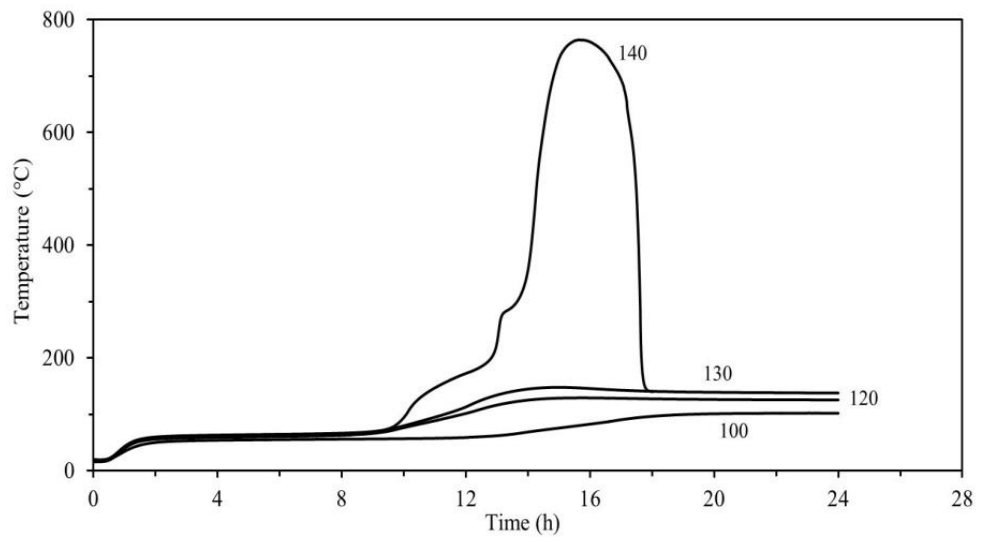

Figure 16. Wire-mesh-cube-testing results for SSSR.

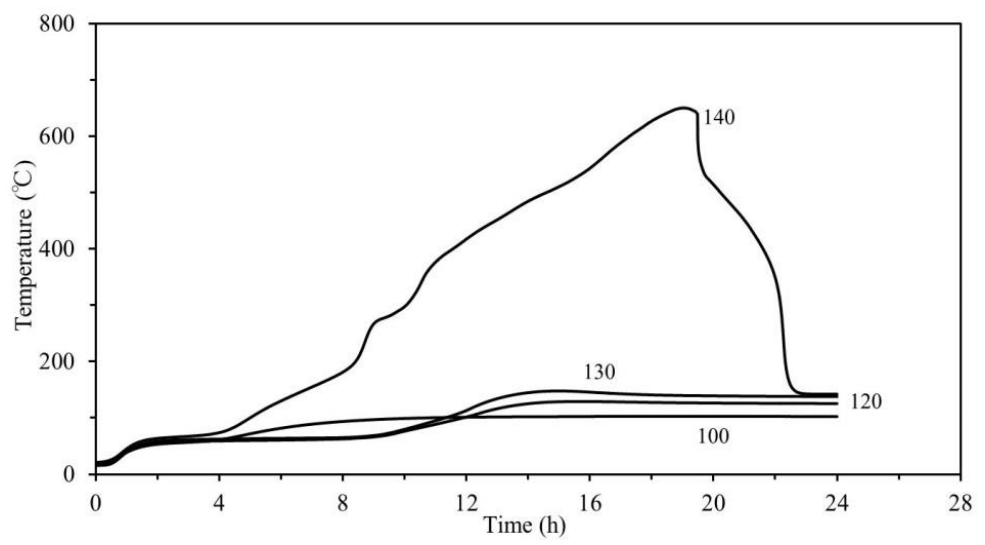

Figure 17. Wire-mesh-cube testing results for fishmeal.

\subsection{Bomb-Type Calorimetry}

In order to study the intensity of combustion when fire occurs following the onset of thermal decomposition, we measured heats of combustion using a bomb-type calorimeter.

The heat-of-combustion results obtained using the C2000 calorimeter are listed in Tables 6 and 7 for SSSR and fishmeal, respectively. Five experiments were conducted on each of the untreated and dry samples, and average values were obtained. As combustion occurs following evaporation, samples that had been left in a thermostat bath at $25{ }^{\circ} \mathrm{C}$ for $10 \mathrm{~d}$, with moisture contents of $5 \%$ or less, were tested. The moisture contents of the dry samples were determined by the air-oven method. The average heat 
of combustion of the untreated SSSR was determined to be $16,714 \mathrm{~kJ} / \mathrm{kg}$, while that of the untreated fishmeal was $18,899 \mathrm{~kJ} / \mathrm{kg}$. Moreover, the average residual heat of combustion of the dry SSSR was $20,049 \mathrm{~kJ} / \mathrm{kg}$, while that of the dry fishmeal was $21,930 \mathrm{~kJ} / \mathrm{kg}$. The amount of heat produced by SSSR and fishmeal are higher by $20 \%$ and $16 \%$, respectively, as a result of drying. The heat of combustion values of RDF (refuse-derived fuel), sewage-sludge fuel, and wood pellets are 16,800-21,800 kJ/kg, $14,880-23,400 \mathrm{~kJ} / \mathrm{kg}$, and $19,700 \mathrm{~kJ} / \mathrm{kg}$, respectively; the heats of combustion of SSSR and fishmeal are similar to those of these biomass fuels [18]. Since most of the moisture evaporates during the combustion process following the onset of heat-induced decomposition, the heats obtained after drying are considered to be reasonable reference values.

Moreover, these results, along with those obtained through wire-mesh-cube testing, reveal that the temperature of the SSSR sample rapidly increases following the onset of thermal decomposition, resulting in an increase in the heat of combustion. Therefore, fire is likely to spread more rapidly in SSSR than in fishmeal.

Table 6. Heats of combustion of SSSR.

\begin{tabular}{ccc}
\hline \multirow{2}{*}{ Run Number } & \multicolumn{2}{c}{ Heat of Combustion (kJ/kg) } \\
\cline { 2 - 3 } & SSSR & Dry SSSR \\
\hline 1 & 16,690 & 20,065 \\
2 & 16,752 & 20,074 \\
3 & 16,719 & 20,003 \\
4 & 16,728 & 20,098 \\
5 & 16,683 & 20,007 \\
Average & 16,714 & 20,049 \\
\hline
\end{tabular}

Table 7. Heats of combustion of fishmeal.

\begin{tabular}{ccc}
\hline \multirow{2}{*}{ Run Number } & \multicolumn{2}{c}{ Heat of Combustion (kJ/kg) } \\
\cline { 2 - 3 } & Fishmeal & Dry Fishmeal \\
\hline 1 & 18,660 & 21,975 \\
2 & 18,886 & 21,885 \\
3 & 19,052 & 21,996 \\
4 & 18,893 & 21,927 \\
5 & 19,003 & 21,865 \\
Average & 18,899 & 21,930 \\
\hline
\end{tabular}

\subsection{Gas Chromatography}

The thermal-analysis results presented above reveal that fermentation occurs between room temperature and $50{ }^{\circ} \mathrm{C}$. We next considered the effect of temperature on oxygen deficiency. Samples were stored in 1-L glass bottles for $10 \mathrm{~d}$, at temperatures ranging from $5{ }^{\circ} \mathrm{C}$ to $50{ }^{\circ} \mathrm{C}$. The effect of fermentation on the gas produced was then investigated by gas chromatography, the results of which are listed in Tables 8 and 9 for SSSR and fishmeal, respectively. The oxygen and carbon dioxide concentrations in relation to the holding temperature are summarized in Figures 18-21.

Under the conditions used in this study, carbon dioxide accounts for the majority of gas produced during SSSR and fishmeal storage. Aside from carbon dioxide, small amounts of flammable gases, such as carbon monoxide and hydrogen, were also detected from fishmeal. Furthermore, more carbon dioxide was produced when moisture was added to both materials. The amount of carbon dioxide produced increased as the temperature increased in the $5-30{ }^{\circ} \mathrm{C}$ range; however, at temperatures above $30^{\circ} \mathrm{C}$, carbon dioxide production was observed to gradually decrease with increasing temperature.

A significant reduction in the amount of generated $\mathrm{CO}_{2}$ was observed in the EOG-treated sample, and no $\mathrm{H}_{2}, \mathrm{CO}$, or $\mathrm{CH}_{4}$ was observed. In the case of SSSR, we found that the concentration of oxygen can drop to below critical levels that adversely affect human health, even when stored below $25^{\circ} \mathrm{C}$, 
especially in samples with high moisture contents. For fishmeal stored below $25{ }^{\circ} \mathrm{C}$, the concentration of oxygen did not decrease to critical levels; however, some sudden drops were observed in fishmeal stored above $25^{\circ} \mathrm{C}$.

When considered alongside the thermal analysis results, fermentation is clearly expected to influence temperature during storage. Therefore, sufficient attention must be paid to humidity and ventilation when storing substances that produce significant amounts of carbon dioxide and decrease oxygen levels, even when stored at low temperatures.

Moreover, based on the thermal and gas analysis results, accidents resulting from oxygen deficiency may occur when a storage facility is well sealed and the amount of oxygen that is circulated is minimal, which results in the consumption of the available oxygen by fermentation, leading to a deficiency of oxygen in the storage facility.

However, fermentation can result in an increase in temperature, leading to the oxidation of fatty acid esters that may subsequently result in a fire when sufficient oxygen is present, and when stored in large deposits in well-insulated facilities. This also applies to storage at temperatures near room temperature.

Table 8. GC data for SSSR stored at various temperatures $\left(5-50{ }^{\circ} \mathrm{C}\right)$.

\begin{tabular}{|c|c|c|c|c|c|c|c|}
\hline \multirow{2}{*}{ Sample } & \multirow{2}{*}{ Storage Temperature } & \multicolumn{6}{|c|}{ GC Analysis Results (\%) } \\
\hline & & $\mathrm{O}_{2}$ & $\mathbf{N}_{2}$ & $\mathrm{H}_{2}$ & $\mathrm{CO}$ & $\mathrm{CH}_{4}$ & $\mathrm{CO}_{2}$ \\
\hline SSSR & \multirow{3}{*}{$5^{\circ} \mathrm{C}$} & 18.6 & 77.4 & - & - & - & 1.3 \\
\hline EOG SSSR & & 19.6 & 77.6 & - & - & - & $<0.1$ \\
\hline $\begin{array}{c}\text { SSSR } \\
+ \text { distilled water } 20 \%\end{array}$ & & 12.3 & 77.8 & - & - & - & 5.8 \\
\hline SSSR & \multirow{3}{*}{$15^{\circ} \mathrm{C}$} & 16.2 & 78.8 & - & - & - & 2.4 \\
\hline EOG SSSR & & 19.3 & 77.4 & - & - & - & $<0.1$ \\
\hline $\begin{array}{c}\text { SSSR } \\
+ \text { distilled water } 20 \%\end{array}$ & & 5.3 & 79.3 & - & - & - & 15.3 \\
\hline SSSR & \multirow{3}{*}{$25^{\circ} \mathrm{C}$} & 1.7 & 79.4 & - & - & - & 16.1 \\
\hline EOG SSSR & & 18.9 & 76.7 & - & - & - & 0.1 \\
\hline $\begin{array}{c}\text { SSSR } \\
+ \text { distilled water20\% }\end{array}$ & & 1.7 & 79.1 & - & - & - & 18.2 \\
\hline SSSR & \multirow{3}{*}{$30^{\circ} \mathrm{C}$} & 1.7 & 81.2 & - & - & - & 16.6 \\
\hline EOG SSSR & & 18.9 & 77.8 & - & - & - & 0.1 \\
\hline $\begin{array}{c}\text { SSSR } \\
+ \text { distilled water20\% }\end{array}$ & & 1.5 & 79.6 & - & - & - & 18.2 \\
\hline SSSR & \multirow{3}{*}{$40^{\circ} \mathrm{C}$} & 2.1 & 79.2 & - & - & - & 15.3 \\
\hline EOG SSSR & & 18.4 & 77.8 & - & - & - & 0.2 \\
\hline $\begin{array}{c}\text { SSSR } \\
+ \text { distilled water } 20 \%\end{array}$ & & 0.9 & 80.3 & - & - & - & 16.4 \\
\hline SSSR & \multirow{3}{*}{$50{ }^{\circ} \mathrm{C}$} & 12.8 & 80.2 & - & - & - & 5.6 \\
\hline EOG SSSR & & 18.6 & 78.0 & - & - & - & 0.1 \\
\hline $\begin{array}{c}\text { SSSR } \\
+ \text { distilled water20\% }\end{array}$ & & 10.2 & 78.9 & - & - & - & 7.5 \\
\hline
\end{tabular}


Table 9. GC data for fishmeal stored at various temperatures $\left(5-50{ }^{\circ} \mathrm{C}\right)$.

\begin{tabular}{|c|c|c|c|c|c|c|c|}
\hline \multirow{2}{*}{ Sample } & \multirow{2}{*}{ Storage Temperature } & \multicolumn{6}{|c|}{ GC Analysis Results (\%) } \\
\hline & & $\mathrm{O}_{2}$ & $\mathbf{N}_{2}$ & $\mathrm{H}_{2}$ & $\mathrm{CO}$ & $\mathrm{CH}_{4}$ & $\mathrm{CO}_{2}$ \\
\hline Fishmeal & \multirow{3}{*}{$5^{\circ} \mathrm{C}$} & 20.4 & 76.7 & - & - & - & $<0.1$ \\
\hline EOG Fishmeal & & 20.6 & 75.2 & - & - & - & $<0.1$ \\
\hline $\begin{array}{c}\text { Fishmeal } \\
+ \text { distilled water20\% }\end{array}$ & & 19.6 & 77.1 & - & - & - & 0.13 \\
\hline Fishmeal & \multirow{3}{*}{$15^{\circ} \mathrm{C}$} & 20.3 & 76.8 & - & - & - & $<0.1$ \\
\hline EOG Fishmeal & & 20.4 & 77.8 & - & - & - & $<0.1$ \\
\hline $\begin{array}{c}\text { Fishmeal } \\
+ \text { distilled water20\% }\end{array}$ & & 18.7 & 77.5 & - & - & - & 0.6 \\
\hline Fishmeal & \multirow{3}{*}{$25^{\circ} \mathrm{C}$} & 20.1 & 77.4 & $<0.1$ & $<0.1$ & - & 0.5 \\
\hline EOG Fishmeal & & 19.5 & 77.7 & - & - & - & 0.2 \\
\hline $\begin{array}{c}\text { Fishmeal } \\
+ \text { distilled water20\% }\end{array}$ & & 4.0 & 83.3 & $<0.1$ & $<0.1$ & - & 11.6 \\
\hline Fishmeal & \multirow{3}{*}{$30^{\circ} \mathrm{C}$} & 14.3 & 81.3 & $<0.1$ & $<0.1$ & - & 0.9 \\
\hline EOG Fishmeal & & 19.8 & 76.5 & - & - & - & 0.2 \\
\hline $\begin{array}{c}\text { Fishmeal } \\
+ \text { distilled water } 20 \%\end{array}$ & & 3.5 & 82.1 & $<0.1$ & $<0.1$ & - & 12.3 \\
\hline Fishmeal & \multirow{3}{*}{$40^{\circ} \mathrm{C}$} & 16.1 & 79.7 & $<0.1$ & $<0.1$ & - & 0.6 \\
\hline EOG Fishmeal & & 20.1 & 76.8 & - & - & - & 0.1 \\
\hline $\begin{array}{c}\text { Fishmeal } \\
+ \text { distilled water } 20 \%\end{array}$ & & 5.7 & 80.5 & $<0.1$ & 0.1 & - & 10.6 \\
\hline Fishmeal & \multirow{3}{*}{$50{ }^{\circ} \mathrm{C}$} & 17.2 & 79.2 & $<0.1$ & 0.1 & - & 0.5 \\
\hline EOG Fishmeal & & 19.2 & 76.5 & - & - & - & 0.2 \\
\hline $\begin{array}{c}\text { Fishmeal } \\
+ \text { distilled water } 20 \%\end{array}$ & & 6.9 & 80.2 & $<0.1$ & 0.2 & - & 8.5 \\
\hline
\end{tabular}

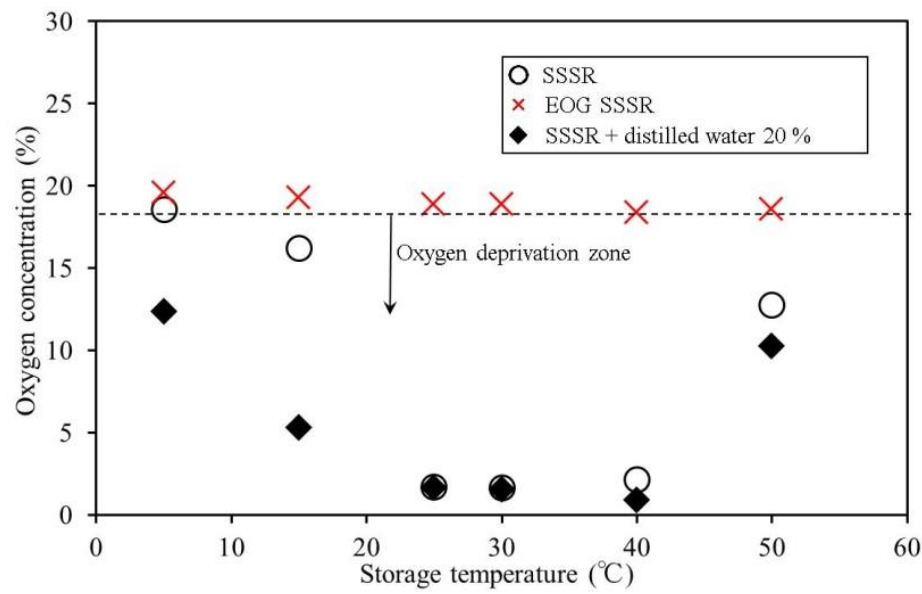

Figure 18. Oxygen concentrations as functions of storage temperature for SSSR samples. 


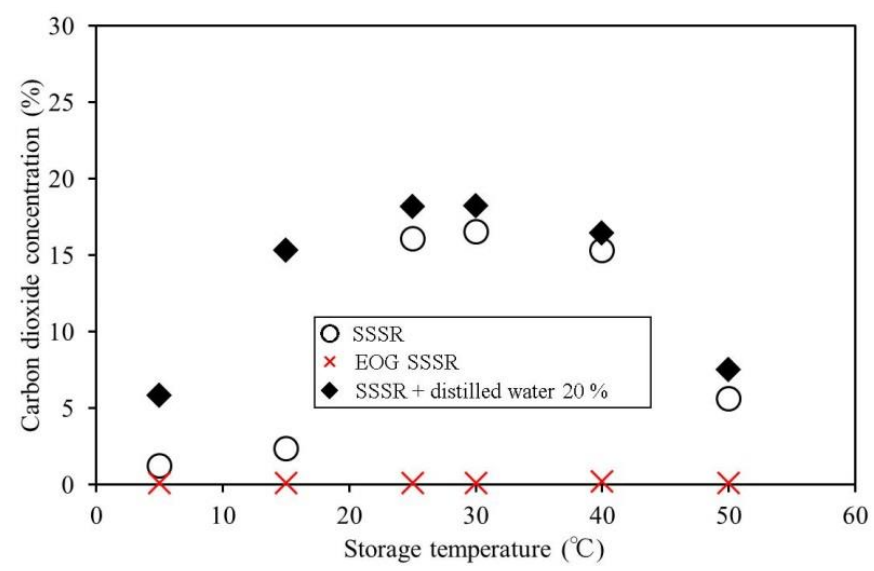

Figure 19. Carbon dioxide concentrations as functions of storage temperature for SSSR samples.

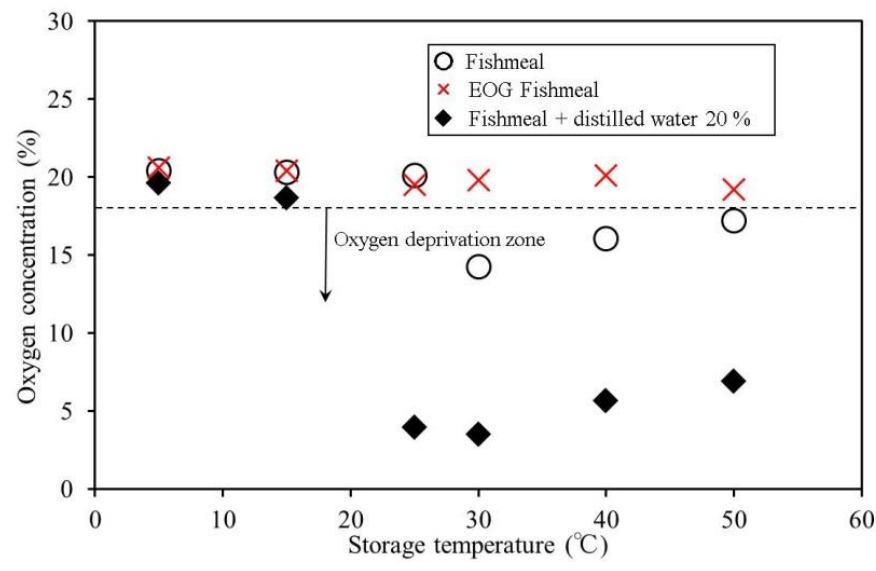

Figure 20. Oxygen concentrations as functions of storage temperature for fishmeal samples.

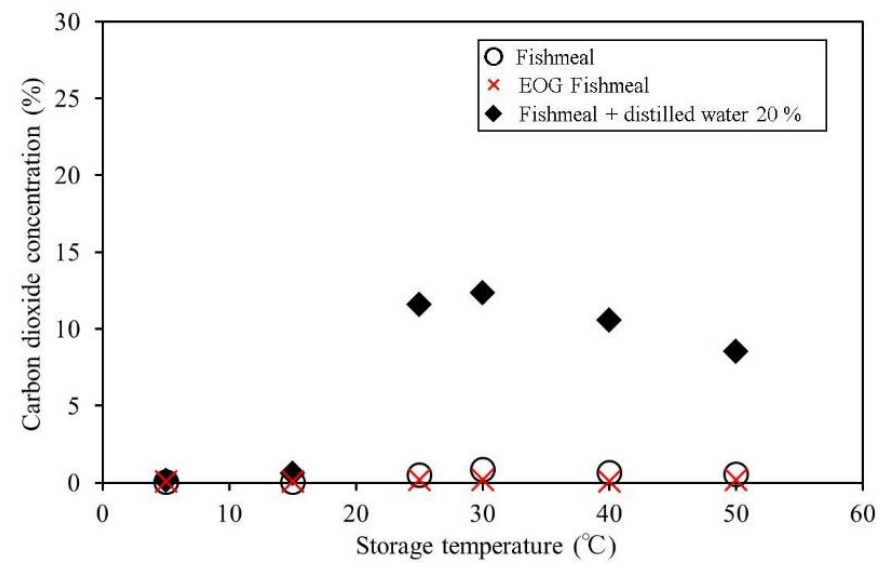

Figure 21. Carbon dioxide concentrations as functions of storage temperature for fishmeal samples.

\section{Estimating the Hazards Associated with Spontaneous Ignition and Oxygen Deprivation by Theoretical Means}

Methods for estimating the hazards of materials stored in high volumes include calculating their activation energies using a theoretical equation, and determining the relationship between pile height and ambient temperature using Semenov [19] or Frank-Kamenetskii theory [9]. These methods have been used to determine the safety of coal storage areas, among other purposes [20]. 
In this study, these numerical methods were used to study the hazards of spontaneous ignition and oxygen deprivation associated with SSSR and fishmeal.

\subsection{Activation Energy}

The data obtained from the SIT experiments were used to calculate activation energies. During the induction period, the temperature increases extremely slowly and in a linear manner over a long time. Since the temperature increases only slightly, and assuming that the heat-generation reaction can be approximated by a zero-order adiabatic process [21], the following equation (Equation (1)) can be established under adiabatic conditions at environmental temperature, $\mathrm{T}$ [3].

$$
\ln \Delta t=\frac{E}{R \cdot T}+\ln \left[\frac{\Delta T \cdot c \cdot \rho}{\Delta H \cdot A}\right]
$$

Here, $\Delta t(\mathrm{~s})$ is the time required for the temperature of the sample to increase from $T(\mathrm{~K})$ to $T+$ $\Delta T(\mathrm{~K}) ; \Delta T$ was obtained from the intersection of the maximum angle of incline and the extension of the holding temperature in each SIT curve; $R\left(\mathrm{~J} \cdot \mathrm{mol}^{-1} \cdot \mathrm{K}^{-1}\right)$ is the gas constant, and $c\left(\mathrm{~J} \cdot \mathrm{kg}^{-1} \cdot \mathrm{K}^{-1}\right)$, $\rho\left(\mathrm{kg} \cdot \mathrm{m}^{-3}\right)$, and $\Delta H\left(\mathrm{~J} \cdot \mathrm{mol}^{-1}\right)$ are the specific heat, density, and heat of reaction of the sample, respectively. $E\left(\mathrm{~J} \cdot \mathrm{mol}^{-1}\right)$ and $A\left(\mathrm{~mol} \cdot \mathrm{m}^{-3} \cdot \mathrm{s}^{-1}\right)$ are the apparent activation energy and the frequency factor of the rate constant of the specified heat-generation reaction [22].

According to Equation (1), $\ln \Delta t$ is linearly related to $1 / T$ (see Figure 22); hence, the slope of this linear relationship, $a$, and the intercept, $b$, can be expressed by Equations (2) and (3), respectively.

$$
\begin{gathered}
a=\frac{E}{R} \\
b=\ln \left[\frac{\Delta T \cdot c \cdot \rho}{\Delta H \cdot A}\right]
\end{gathered}
$$

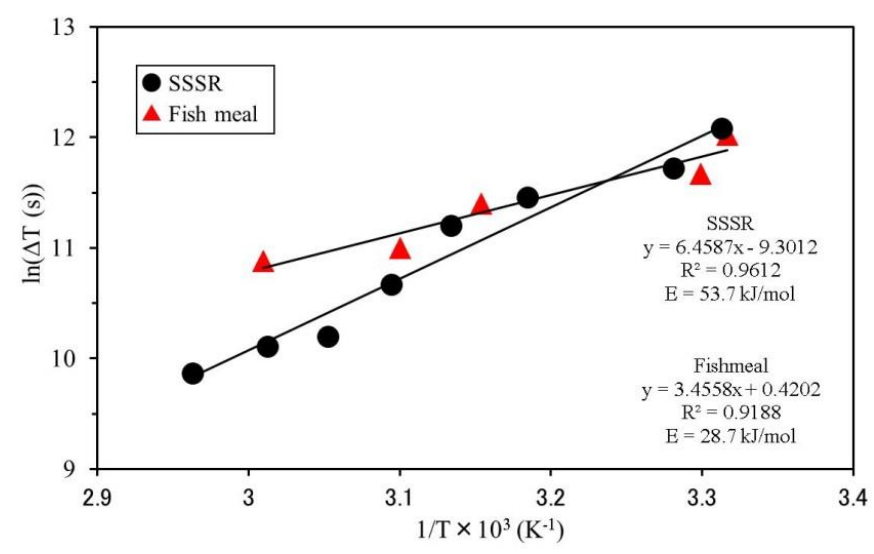

Figure 22. Relationships between $\ln \Delta \mathrm{t}$ and $1 / \mathrm{T}$ for SSSR and fishmeal.

Through application of Equation (2), we determined the activation energies for temperatures between room temperature $\left(\sim 25^{\circ} \mathrm{C}\right)$ and approximately $50{ }^{\circ} \mathrm{C}$, which is the temperature range in which, based on thermal and gas analyses, the small amount of heat generated by fermentation and oxidation is estimated to have a potentially high impact on temperature. The results revealed that the activation energy for SSSR was $53.7 \mathrm{~kJ} / \mathrm{mol}$, whereas that for fishmeal was $28.7 \mathrm{~kJ} / \mathrm{mol}$. Within the temperature range of these calculations, fishmeal exhibited a lower activation energy, indicating that fishmeal requires less energy to stimulate the reaction. 


\subsection{Relationship between Temperature and Pile Height}

SSSR and fishmeal are generally packed in bags that are piled several layers high in cubic formations in warehouses. Knowing that temperature distributions exists in storage, Frank-Kamenetskii theory [9] was used to calculate the relationship between pile height and the temperature at which spontaneous ignition and oxygen deprivation occur.

Regarding the thermal-ignition limit, the Frank-Kamenetskii parameter $\delta c$, which is related to the critical ignition temperature of a self-heating ignition process, can be obtained by the following expression:

$$
\delta_{c}=\frac{\Delta H \cdot E \cdot r^{2} \cdot A}{\lambda \cdot R \cdot T_{c}^{2}} \exp \left[-\frac{E}{R \cdot T_{c}}\right]
$$

Equation (4) leads to Equation (5):

$$
\ln T_{c}+\frac{(E / R)}{2 T_{\mathcal{c}}}=\ln r+\frac{1}{2} \ln \left[\frac{(\Delta H \cdot A)(E / R)}{\delta_{\mathcal{c}} \cdot \lambda}\right]
$$

and Equation (6) can be derived by substituting Equations (2) and (3) into Equation (5) and eliminating $(\mathrm{E} / \mathrm{R})$ and $\ln (\Delta \mathrm{H} \mathrm{A})$ :

$$
\ln T_{c}+\frac{a}{2 T_{c}}=\ln r+\frac{1}{2}\left[\ln \left(\frac{a \cdot \Delta T \cdot c \cdot \rho}{\delta_{c} \cdot \lambda}\right)-b\right]
$$

In Equation (6), $T_{c}$ is the critical ambient temperature at which the onset of a reaction is observed, while $\delta c$ is the previously defined Frank-Kamenetskii parameter $(\delta c=2.52$ for a cube), and the values of a (SSSR: 6.4587, fishmeal: 3.4558) and b (SSSR: 9.3012, fishmeal: 0.4202) were obtained from the activation-energy relationships shown in Figure 22. In addition, $\Delta \mathrm{T}$ was assumed to be $1 \mathrm{~K}[23,24]$, and the parameters listed in Table 10 were used in Equation (6).

Table 10. SSSR and fishmeal parameters.

\begin{tabular}{cccc}
\hline \multirow{2}{*}{ Parameter } & Units & \multicolumn{2}{c}{ Value } \\
\cline { 3 - 4 } & & SSSR & Fishmeal \\
\hline Frank-Kamenetskii parameter, $\delta_{c}$ & Non-dimensional & \multicolumn{2}{c}{2.52} \\
Rise in heat, $\Delta T$ & $\mathrm{~K}$ & 1 & \\
Specific heat capacity, $c$ & $\mathrm{~J} \cdot \mathrm{kg}^{-1} \cdot \mathrm{k}^{-1}$ & $2.44 \times 10^{3}$ & $2.63 \times 10^{3}$ \\
Bulk density, $\rho$ & $\mathrm{kg} \cdot \mathrm{m}^{-3}$ & $0.2-0.4$ & \\
\hline Heat thermal conductivity, $\lambda$ & $\mathrm{J} \cdot \mathrm{s}^{-1} \cdot \mathrm{m}^{-1} \cdot \mathrm{K}^{-1}$ & 0.2 & 0.4 \\
\hline
\end{tabular}

Frank-Kamenetskii theory [9] was used to calculate the critical holding temperature at which the onset of a reaction is observed as a function of pile height; these results are displayed in Figures 23 and 24. We also examined the effect of changes in pile density on the calculated results.

The results reveal that the temperature at which a reaction (heat accumulation and temperature increase) is triggered decreases proportionately with increasing pile height. A comparison of the SSSR and fishmeal data reveal that there is a larger temperature decrease in proportion to increasing pile height in the case of fishmeal compared with SSSR.

Changes in pile density were found to have a greater impact on the relationship between temperature and pile height for fishmeal than SSSR, as shown in Figures 23 and 24. In many instances, SSSR and fishmeal are piled to heights of approximately $3 \mathrm{~m}$ or greater in storage areas.

Based on the results of the calculations performed in this study, the critical ambient temperature at which a reaction (heat accumulation and temperature increase) occurs is estimated to be between 20-30 ${ }^{\circ} \mathrm{C}$, at a bulk density of $0.3 \times 10^{3} \mathrm{~kg} / \mathrm{m}^{3}$, and a pile height of $3 \mathrm{~m}$. However, these values are merely estimations, and various factors (e.g., excessive piling, adiabatic conditions, and the volume of outside-air inflow) are likely to affect these values. 
The calculated results in this study reveal that sufficient attention should be paid to pile height in order to prevent accidents due to spontaneous ignition and oxygen deprivation in storage areas.

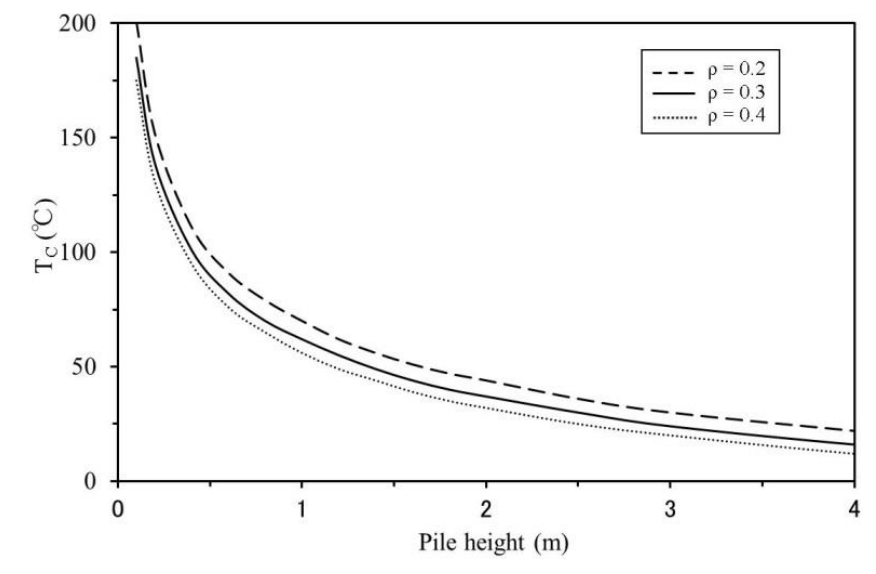

Figure 23. Frank-Kamenetskii results for SSSR.

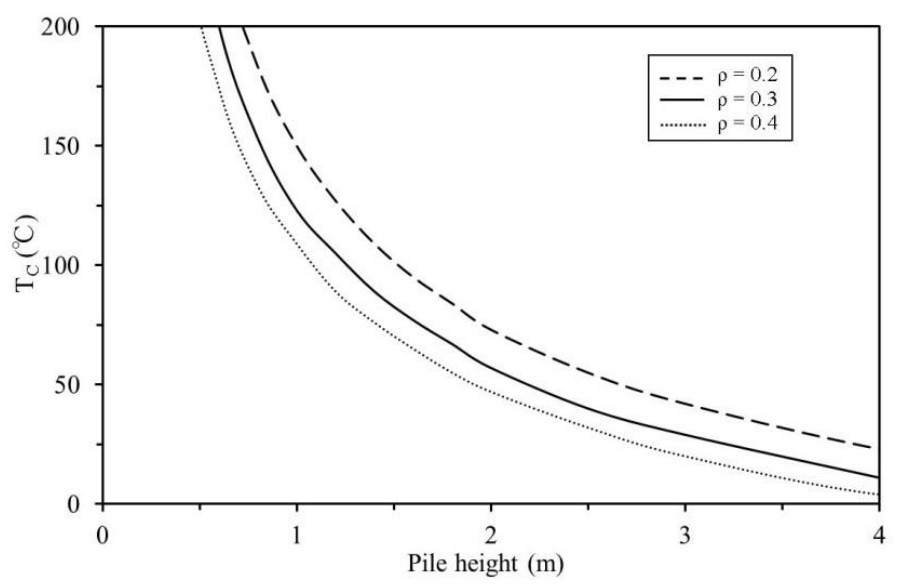

Figure 24. Frank-Kamenetskii results for fishmeal.

\section{Conclusions}

Based on the experimental results, the following conclusions are made:

(1) TG-DTA results reveal that the thermal decomposition of both SSSR and fishmeal occur in three separate phases, but overall, SSSR exhibits a more active heat generation reaction. Moreover, the temperature at which self-heat generation began is about $173{ }^{\circ} \mathrm{C}$ in SSSR and $187^{\circ} \mathrm{C}$ in fishmeal. Fermentation and oxidation led to an increase in temperature, and once the temperature reached the above-mentioned value, self-heat generation began, leading to fire due to spontaneous ignition.

(2) The results of the C80 and TAM-calorimetry experiments reveal that fermentation is likely to be involved in generating heat in SSSR; this generation occurs from the commencement of the experiment to a temperature close to $50^{\circ} \mathrm{C}$. As for fishmeal, its fatty acid esters are believed to have a greater impact on the heat generated.

(3) The results of the SIT-calorimetry experiments reveal that less time is required for the temperature to rise in the SSSR sample compared with fishmeal following heat generation, even when maintained at the same ambient temperature. When SSSR or fishmeal is maintained at ambient temperatures near $40{ }^{\circ} \mathrm{C}$, a temperature increase of up to $250{ }^{\circ} \mathrm{C}$ takes place within approximately 
$30 \mathrm{~h}$. These results indicate that caution should be taken in order to avoid spontaneous ignition, particularly during the summer.

(4) The wire-mesh-cube-testing and bomb-type calorimetry results reveal that the SSSR temperature rose more sharply following commencement of thermal decomposition, while the observed maximum temperature was also higher than that of fishmeal. Moreover, the heats of combustion of both SSSR and fishmeal were similar to those of existing recycled fuels.

(5) The GC results reveals that the oxygen concentration can drop below critical safety thresholds in the case of SSSR, even when stored below $25^{\circ} \mathrm{C}$, particularly when the moisture content is high. Although fishmeal stored below $25^{\circ} \mathrm{C}$ does not exhibit any decrease in oxygen concentration, some sudden drops were observed when stored above $25^{\circ} \mathrm{C}$.

(6) Accidents resulting from oxygen deficiency may occur when a storage facility is well sealed and the amount of circulated oxygen is minimal, allowing the oxygen to be consumed by fermentation, and leading to a deficiency of oxygen in the storage facility. However, when sufficient oxygen is present and the material is stored in large deposits in a well-insulated facility, fermentation is likely to cause the temperature to increase, leading to the oxidation of fatty acid esters and a subsequent fire. This also applies to storage temperatures near room temperature.

(7) Numerical calculations demonstrate that pile height should be considered in order to prevent spontaneous ignition and oxygen deprivation in storage facilities. As a safety measure, workers should be required to carry small gas detectors and, in the case of high storage volumes, the gas concentrations should be recorded when materials are shipped into and out of the storage area. In addition, to prevent accidents due to oxygen deprivation while protecting the health of the workers, the oxygen concentration in the storage area should be monitored with an oximeter that can be read from outside the storage area. Furthermore, the storage area should be ventilated, and its safety verified before entering.

Author Contributions: N.M.: manuscript writing and data analysis and interpretation; H.K.: designing the study; Y.I.: designing the study; T.S.: designing the study. All authors participated in writing this paper.

Funding: This research received no external funding.

Conflicts of Interest: The authors declare no conflicts of interest.

\section{References}

1. Li, X.-R.; Lim, W.-S.; Iwata, Y.; Koseki, H. Thermal Behavior of Sewage Sludge Derived Fuels. Therm. Sci. 2008, 12, 137-148. [CrossRef]

2. Shimizu, Y.; Wakakura, M.; Arai, M. Heat Accumulations and Fire Accidents of Waste Piles. J. Loss Prev. Process Ind. 2009, 22, 86-90. [CrossRef]

3. Yasuhara, A.; Amano, Y.; Shibamoto, T. Investigation of the Self-Heating and Spontaneous Ignition of Refuse-Derived Fuel (RDF) During Storage. Waste Manag. 2010, 30, 1161-1164. [CrossRef] [PubMed]

4. Murasawa, N.; Koseki, H. Investigation of heat generation from biomass fuels. Energies 2015, 8, 5143-5158. [CrossRef]

5. Ogawa, G.; Fujita, A. Recent Progress in Soy Sauce Production in Japan. In Cereals for Food and Beverages, Recent Progress in Cereal Chemistry and Technology; Academic Press: London, UK, 1980; pp. 381-394.

6. Jun, A. Apostichopus japonicus: Fisheries, Trade, and Foodways in Japan. In Developments in Aquaculture and Fisheries Science; Elsevier: Amsterdam, The Netherlands, 2015; Volume 39, Chapter 22; pp. 399-421.

7. Liu, C.; Hotta, Y.; Santo, A.; Hengesbaugh, M.; Watabe, A.; Totoki, Y.; Allen, D.; Bengtsson, M. Food waste in Japan: Trends, current practices and key challenges. J. Clean. Prod. 2016, 133, 557-564. [CrossRef]

8. Murasawa, N.; Koseki, H.; Iwata, Y. Lessons Learned from Accidents of Soy Sauce Squeezing Residue—Risks of Spontaneous Ignition and Oxygen Deficiency. Loss Prev. Bull. 2012, 224, 14-17.

9. Frank-Kamenetskii's, D.A. Diffusion and Heat Transfer in Chemical Kinetics; Plenum Press: New York, NY, USA, 1969; p. 374. 
10. Gillespie, E.H.; Jackson, J.M.; Owen, G.R. Ethylene oxide sterilisation-is it safe? J. Clin. Pathol. 1979, 32, 1184-1187. [CrossRef] [PubMed]

11. Kotoyori, T.; Maruta, M. An adiabatic self-ignition testing apparatus. Thermochim. Acta 1983, 67, 35-44. [CrossRef]

12. The United Nations. Recommendations on the Transport of Dangerous Goods, Manual of Tests and Criteria, 4th ed.; The United Nations: San Francisco, CA, USA, 2003.

13. Gray, B.F.; Griffiths, J.F.; Hasko, S.M. Spontaneous ignition hazards in stockpiles of cellulosic materials: Criteria for safe storage. J. Chem. Technol. Biotechnol. Chem. Technol. 1984, 34, 453-463. [CrossRef]

14. Hogland, W.; Marques, M. Physical, biological and chemical processes during storage and spontaneous combustion of waste fuel. Resour. Conserv. Recycl. 2003, 40, 53-69. [CrossRef]

15. Lohrer, C.; Krause, U.; Steinbach, J. Self-Ignition of Combustible Bulk Materials under Various Ambient Conditions. Process Saf. Environ. Prot. 2005, 83, 145-150. [CrossRef]

16. Rychlý, J.; Matisová-Rychlá, L.; Lazár, M.; Slovák, K.; Strlič, M.; Kočar, D.; Kolar, J. Thermal Oxidation of Cellulose Investigated by Chemiluminescence. The Effect of Water at Temperatures above $100{ }^{\circ} \mathrm{C}$. Carbohydr. Polym. 2004, 58, 301-309. [CrossRef]

17. Li, X.R.; Koseki, H.; Momota, M. Evaluation of Danger from Fermentation-Induced Spontaneous Ignition of Wood Chips. J. Hazard. Mater. 2006, 135, 15-20. [CrossRef] [PubMed]

18. Koseki, H. Evaluation of Various Solid Biomass Fuels Using Thermal Analysis and Gas Emission Tests. Energies 2011, 4, 616-627. [CrossRef]

19. Semenov, N.N. Theories of Combustion Process. J. Phys. 1928, 48, 571-582.

20. Jones, J.C. Calculation of the Frank-Kamenetskii critical parameter for a cubic reactant shape from experimental results on bituminous coals. Fuel 1999, 78, 89-91. [CrossRef]

21. Kotoyori, T. Critical Ignition Temperature of Wood Sawdust Layers. Ind. Saf. Inst. Rep. 1985, 85, 33-44.

22. Babrauskas, V. Ignition Handbook; Fire Science Publishers: San Diego, CA, USA, 2003.

23. Kotoyori, T. Critical temperatures for the thermal explosion of liquids. Combust. Flame 1993, 312, 307-312. [CrossRef]

24. Kotoyori, T. Critical ignition temperatures of chemical substances. J. Loss Prev. Process Ind. 1989, 2, 16-21. [CrossRef] 